\title{
«Perdona / termine»: Los actos de habla directivos en mediaciones laborales*
}

\author{
«Perdona / termine»: The directive speech acts in labour mediation
}

\author{
Susana Ridao Rodrigo \\ Universidad de Almería
}

\begin{abstract}
Resumen. El objetivo de este artículo se centra en estudiar cómo se codifican los actos de habla directivos desde el punto de vista lingüístico en contextos negociadores. El marco teórico del que se parte es la teoría de los actos de habla ideada por Austin (1962) y Searle (1969 y 1975). El corpus analizado está compuesto por cinco mediaciones laborales celebradas en Almería (España) entre los años 2003 y 2006. Desde la dimensión cuantitativa destaca el elevado empleo del imperativo, que representa el $41.9 \%$ de los actos de habla directivos presentes en el corpus. Además, también el uso del imperativo es reseñable desde la perspectiva cualitativa, porque el enfoque pragmático demuestra que el contexto resulta determinante para valorar si los actos de habla realzan o dañan la imagen del receptor, a pesar de que el enunciado elegido esté asociado tradicionalmente a formas corteses o descorteses.
\end{abstract}

Palabras clave: pragmática, actos de habla directivos, mediaciones laborales, Austin, Searle.

Abstract. The aim of this paper is to describe from a linguistic point of view how directive speech acts are encoded in the context of labour mediation. The theoretical background takes the theory

Data de recepción: 03-01-2019 - Data de aceptación: 02-05-2019.

* Este artículo nace al amparo del centro de investigación CEMyRI y del proyecto de investigación «Pragmática y gramática en la historia del español: la expresión de la cortesía en el español clásico» (FFI2014-53113-P), financiado por el Ministerio de Economía, Industria y Competitividad, con fecha de ejecución 2015-2018. 
of speech acts as conceived by Austin (1962) and Searle (1969 and 1975) as a starting point. The corpus to be analysed consists of five labour mediation sessions held in Almería (Spain) between 2003 and 2006. From a qualitative perspective, the most salient feature is the high frequency of the imperative, which represents $41.9 \%$ of the directive speech acts present in the corpus. However, the use of the imperative is also significant from a qualitative point of view because the pragmatic approach shows that the context is decisive in assessing whether speech acts enhance or damage the face of the addressee, independently of the forms of address - traditionally considered polite or impolite - in a given utterance.

Keywords: pragmatics, directive speech acts, labour mediation, Austin, Searle.

\section{INTRODUCCIÓN}

Los actos de habla están presentes en las conversaciones cotidianas, como consecuencia de que transmiten las intenciones de los hablantes que las cifran. Cuando un individuo quiere influir en la conducta de otro, elige entre distintas maneras de codificar el mensaje con las que se muestra más o menos cortés. El consejo, la petición o la orden pueden ser actos de habla cuyas fronteras están muy difusas; sobre esta cuestión resulta interesante incluir este fragmento extraído de La Cartuja de Parma de Stendhal: «Pero ya que optas, hasta nueva orden, por las medias moradas, el conde, que conoce bien la Italia actual, me ha encargado que te transmita un consejo: no importa que te creas o no lo que te enseñen, pero jamás plantees ninguna objeción» (1987: 232; cursiva en el original).

Sin duda, la lengua es el medio por el que se comunican los seres humanos, si bien es cierto que los mensajes se cifran tanto de manera verbal como mediante mecanismos no verbales. Precisamente en el enunciado emitido aparecen implícitas las estrategias de cortesía — entendiendo la cortesía como un mecanismo regulador de los intercambios comunicativos en los que deben evitarse los actos amenzadadores de la imagen (Brown y Levinson 1987) —, aspecto imprescindible para mantener buenos vínculos con los interlocutores (García Fernández 2010: 9). La conexión existente entre el decir y el hacer se basa en la divergencia entre enunciado y acto de habla, dado que, cuando se elige un enunciado, se está produciendo una acción (Garrido Medina 1999: 3881). Emitir un acto de habla directivo implica que el hablante coarte la libertad de acción del oyente; pese a todo, existe un abanico de posibilidades a la hora de cifrar este tipo de actos de habla.

El objetivo de este modesto artículo es analizar cómo se cifran — desde el punto de vista lingüístico - los actos de habla directivos en un corpus de mediaciones 
laborales. Por tanto, la fundamentación teórica parte de la conocida teoría de los actos de habla de Austin (1962) y Searle (1969 y 1975) y se centra en los actos de habla directivos. En cuanto al análisis, se ofrece un estudio abordado tanto desde la perspectiva cuantitativa como desde el enfoque cualitativo. En el corpus estudiado se han encontrado ocho formas de cifrar los actos de habla directivos: el imperativo, la perífrasis verbal, el presente de indicativo, el presente de subjuntivo, la oración condicional, el pretérito imperfecto de indicativo, el infinitivo y la interrogación. Además, de manera colateral, se reflexiona sobre la influencia de las estrategias de (des)cortesía a la hora de cifrar lingüísticamente un acto de habla directivo.

\section{EL NACIMIENTO DE LA PRAGMÁTICA: LOS ACTOS DE HABLA}

Se le debe a Morris (1938) la introducción del término pragmática en las ciencias del lenguaje, al aseverar que esta parte de la semiosis se interesa por la relación de los signos con los intérpretes, en tanto que investiga los fenómenos psicológicos, biológicos y sociológicos que concurren en el funcionamiento de los signos. A partir de la segunda mitad del siglo XX, con las contribuciones sobre los actos de habla efectuadas por los filósofos del lenguaje Austin (1962) —aunque las famosas conferencias de este investigador han de ubicarse cronológicamente en 1955- y Searle (1969 y 1975), se inicia una nueva tendencia investigadora denominada lingüística de la comunicación (Gutiérrez Ordóñez 2002: 143). La pragmática puede ser interpretada como un intento de hallar el sentido de la conducta lingüística (Reyes, 1994[1990]: 15). En realidad, «hablar de discurso es, ante todo, hablar de una práctica social, de una forma de acción entre las personas que se articula a partir del uso lingüistico contextualizado, ya sea oral o escrito» (Calsamiglia y Tusón 1999: 15; cursiva en el original).

La teoría de los actos de habla propuesta en la segunda mitad del siglo XX por Austin (1962) y Searle (1969 y 1975) no solo gozó de gran repercusión en el campo de la lingüística estructural, sino que también supuso un gran influjo en el ámbito del psicoanálisis, la antropología, la sociología o la filosofía (Cuamba Herrejón 2014: 83). La influencia de esta teoría supera la tradición saussureana que distingue entre significante y significado al concebir la lengua como acción, y en estos intercambios comunicativos el contexto va a resultar determinante para su correcta interpretación (García Fernández 2010: 9). Como indica Siebold, «esta teoría presenta una explicación sistemática de lo que hacemos cuando hablamos» (2008: 43). Al entender Austin (1962) el lenguaje como acción, rompe la tradición del positivismo lógico que consideraba que el lenguaje tenía una función meramente descriptiva, de ahí que los enunciados se pudieran describir como verdaderos o falsos (Ballesteros Martín 
1999: 51). Para Dottori (2019: 169-170), esta teoría se caracteriza por ubicarse en una intersección entre el lenguaje y la acción.

A través de los actos de habla se llevan a cabo acciones, como prometer, pedir información u ordenar, entre otras muchas. Los enunciados poseen fuerza ilocutiva, entendiendo por tal el carácter de promesa, petición, ruego u orden, por ejemplo. Estos enunciados están compuestos por tres tipos de actos: el hecho de decir algo es el denominado acto locutivo, el hecho de hacer algo al decir algo recibe el nombre de acto ilocutivo, y cuando producen unos efectos en el interlocutor se trata de un acto perlocutivo (Garrido Medina 1999: 3881). Se ha de tener en cuenta «que un acto de habla determinado solo es reconocido como tal en las circunstancias sociales adecuadas» (RAE-ASALE 2009: 794), de forma que un acto de absolución únicamente tiene validez si es pronunciado por un juez en el contexto apropiado. Por su parte, Searle le otorgó a los postulados de Austin un enfoque más lingüístico y más gramatical, en tanto que incidió en la relación existente entre acto de habla y estructura sintáctica, estableciendo paralelismos entre la función comunicativa desempeñada por el acto de habla y la caracterización lingüística de los enunciados (Morales Manrique 2010: 161).

Hay que tener en cuenta la existencia de actos de habla indirectos, que son aquellos en los que hay divergencia entre el ciframiento lingüístico del enunciado y la intención comunicativa del hablante (Searle 1975). Sobre esta cuestión, argumenta Muldon (1993: 203) que, aunque este concepto de actos de habla indirectos esté muy bien definido, genera dificultades a la hora de ser aplicado en estudios empíricos. No se debe establecer una correspondencia inequívoca, por ejemplo, entre la oración imperativa y las órdenes (Garrido Medina 1999: 3887). La diferenciación entre actos de habla ha de establecerse en función de criterios lingüísticos - fundamentados en la estructura proposicional - y criterios pragmáticos - fundamentados en la interpretación del acto de habla - (Haverkate 1994: 156). Cisneros Estupiñán (2007: 35-36) recuerda que un hablante conjuga, de una parte, la competencia comunicativa que le permite comunicarse con sus semejantes y, de la otra, las estrategias de cortesía que logran alcanzar una buena imagen tanto de sí mismo como del interlocutor. Según Garrido Medina, «en general, los actos indirectos permiten salvar la imagen pública del hablante o la del oyente y evitar el carácter descortés que tienen intrínsecamente ciertos actos directos» (1999: 3888).

Con frecuencia se producen malentendidos interculturales como consecuencia de que existen divergencias que afectan tanto a la utilización como a la ejecución de los actos de habla (Querol Bataller 2018: 264). De hecho, según indica Duffé Montalván (2017: 177), los manuales dedicados a la enseñanza de una lengua extranjera que han sido publicados en los últimos años abarcan los actos de habla, en tanto que están 
relacionados con el enfoque pragmático, a la vez que se tienen en cuenta para elaborar los objetivos, los contenidos y, por supuesto, los ejercicios. Desde otro enfoque, estudios recientes se han interesado en los actos de habla utilizados en contextos digitales con muy dispares finalidades: espionaje, control, detección de conflictos u optimización de respuestas automáticas. En tales casos suelen establecerse tres o cuatro categorías (por ejemplo, comisivos o declarativos, asertivos y expresivos) con el objetivo de simplificar, aunque esta clasificación automática puede inducir a error al descartar la posibilidad de que sea un cerebro humano quien desambigüe ciertos mensajes (Ainciburu, 2017: 46).

\section{LOS ACTOS DE HABLA DIRECTIVOS}

Si bien es cierto que Austin (1962) ya ofrecía una taxonomía de cinco tipos de actos de habla (a saber, judicativos, ejercitativos, compromisorios, comportativos y expositivos), la clasificación que ha calado entre los estudiosos de la pragmática fue la establecida por su discípulo Searle (1969), como muestra el hecho de que la aportación a la Gramática Descriptiva de la Lengua Española de Garrido Medina (1999: 3888) se hace eco de ella:

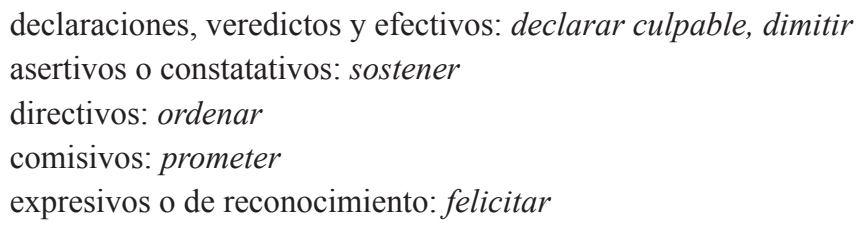

Para Ainciburu la economía lingüística representa un obstáculo bastante relevante en la distinción de categorías completamente discriminantes a la hora de clasificar los actos de habla, al tiempo que puede existir un solapamiento de recursos lingüísticos en determinadas construcciones (2017: 49). Refiriéndose a los actos de habla expresivos en concreto, Hernández Toribio \& Mariottini (2018: 18) rechazan un análisis de tales actos de manera aislada, sino que abogan por tener en cuenta su relación con el desarrollo de la interacción. Precisamente, en la cooperación necesaria para que la comunicación sea posible los participantes comunican más de lo que están diciendo y esto es aplicable a cualquier tipología de acto de habla (Redondo González, 2018: 12). Centrados en los actos directivos, estos «reflejan situaciones en las que la enunciación se dirige al receptor y le traslada la carga de acción» (Molina, 2008: 18). Se trata de un contexto donde el oyente puede ejecutar la acción que ha solicitado el emisor, de 
lo cual se deduce que en la condición preparatoria se ha tenido en cuenta el parámetro de control (Muldon, 1998: 239). Para que esta situación no resulte excesivamente descortés, la función directiva posee mecanismos que aminoran la carga ilocutiva del acto, de tal manera que «el oyente no vea su consentimiento como una sumisión al hablante, sino como una decisión o consentimiento personal» (Molina 2008: 18). Los actos de habla directivos se caracterizan lingüísticamente por: (1) el empleo frecuente de los modos verbales imperativo y subjuntivo, (2) la utilización de recursos formales de carácter léxico como son los performativos explícitos y los verbos modales, y (3) elementos suprasegmentales como la entonación; a su vez, los enunciados indicativos o interrogativos en función del contexto pueden asumir el valor directivo (Núñez 1991: 357-358).

Los mandatos y las peticiones son los actos de habla que amenazan en mayor medida la imagen negativa del receptor, esto es, sitúan el foco de atención en la libertad de acción (Brown y Levinson 1987: 65). Es obvio que el emisor influye de manera directa en la libertad de acción del destinatario, a la vez que puede verse dañada la imagen del emisor (Binti Ismail 2013: 50). Según Ballesteros Martín (1999: 126), los mandatos pertenecen al grupo de los actos directivos, en particular a la modalidad de los actos exhortativos impositivos. Aparte, los mandatos también pueden ser denominados órdenes. En este punto, conviene recordar la borrosa frontera existente en algunos casos entre la petición y la orden o el mandato. Los actos de habla considerados mandatos suelen producirse en la comunicación cotidiana entre participantes con relaciones jerárquicas (Shahila Mansor \& Ridruejo Alonso 2014: 72). Sobre esta cuestión, Iglesias Recuero (2010: 14) advierte de la relevancia de repensar y redefinir las dimensiones de poder y de distancia en función de variables cronológicas y sociales.

El imperativo y las expresiones realizativas constituyen en la actualidad la forma más directa de expresión de un acto directivo, lo que implica un alejamiento de las formas de cortesía y un acercamiento a las de descortesía (Iglesias Recuero 2016: 978). Según Almeida Cabrejas, «mandar presenta, efectivamente, una fuerte exigencia sobre el emisor de la orden, que resulta ser, en la práctica totalidad de los casos, una persona con autoridad sobre aquella o aquellas a quienes se dirige la orden» (2011: 188; cursiva en el original). En el modelo cognoscitivo idealizado proposicional sobre el acto de ordenar, Pérez Hernández (2000: 385) argumenta que se han de tener en cuenta seis variables a la hora de interpretar dicho acto: costo/beneficio, opcionalidad, indirección, poder social, distancia social y grado de directividad del acto.

La aportación efectuada por Searle sobre los actos de habla directos e indirectos ha recibido críticas de diversos autores por la existencia de un desajuste en cuanto a la frecuencia de uso, dado que en los intercambios cotidianos asiduamente se emplean 
actos de habla indirectos y en muy menor medida los directos (Ridao 2010: 127). Ciertamente, la cortesía ha sido entendida como un recurso que justifica el empleo de los actos de habla indirectos (Haverkate 1994: 153). En palabras de Haverkate, «el hablante socialmente competente sabe que la selección de una u otra categoría repercute en un efecto perlocutivo radicalmente distinto» (1994: 149). Para la expresión de enunciados exhortativos hay tres formas de comportamiento interactivo, las cuales siguen este orden: en primer lugar, cortesía negativa; en segundo, falta de cortesía; y, por último, descortesía (Haverkate 1994: 152).

\section{CORPUS Y MÉTODO}

Las transcripciones analizadas fueron publicadas en Ridao (2009); se trata de cinco mediaciones laborales que se celebraron en el Sistema Extrajudicial de Resoluciones de Conflictos Colectivos Laborales de Andalucía (SERCLA) entre los años 2003 y 2006 en Almería capital. El corpus completo está formado por cuatro horas de grabación; exactamente la primera mediación dura 55 minutos y 36 segundos; la segunda, 29 minutos y 6 segundos; la tercera, 24 minutos y 14 segundos; la cuarta, 44 minutos y 35 segundos; la quinta, 84 minutos y 42 segundos. Dado que esta técnica de resolución de conflictos es relativamente reciente en España, se han publicado diversos manuales de apoyo; en la guía elaborada por Munduate et alii la mediación es definida como «la intervención de una tercera parte, competente e imparcial, en una disputa, con el propósito de ayudar a las partes a resolver sus diferencias y a mejorar sus relaciones en el futuro, proveyéndoles de un ambiente seguro» (2008: 12). Además, en RAEASALE (2014) en la segunda acepción de la entrada mediación indica: «f. Der. Actividad desarrollada por una persona de confianza de quienes sostienen intereses contrapuestos, con el fin de evitar o finalizar un litigio».

Los contextos comunicativos sometidos a estudio se caracterizan por la existencia de tres grupos de participantes: (1) la comisión, formada por un presidente y cuatro miembros, es la encargada de facilitar el diálogo entre las partes enfrentadas; (2) la representación empresarial, que vela por los intereses económicos de dicha corporación; y (3) la representación de los trabajadores, que defiende los derechos de los empleados. Normalmente en representación de la empresa suelen asistir al acto mediador dos o tres miembros; en cambio, de la parte trabajadora con frecuencia acude un número bastante más elevado, ya que al representante de los trabajadores le pueden acompañar empleados. Con respecto a la sala en la que se han celebrado las cinco mediaciones analizadas, en ella se ubican dos mesas contiguas de grandes dimensiones: una mesa ovalada en la que se sitúan los miembros de la comisión y, 
anexa a esta, una mesa rectangular en cuya parte derecha — desde la perspectiva de la comisión - se sienta la parte empresarial y en cuya parte izquierda se coloca la representación laboral. El acto comienza con la intervención del presidente de la comisión, quien resume el tema del conflicto y, seguidamente, le cede el turno a las partes enfrentadas para que lleguen a un acuerdo. Un estudio más detallado sobre el marco comunicativo de este género discursivo puede consultarse en Ridao (2014); especialmente relevante resultan las apreciaciones sobre los ruidos —entendiendo por tales todas las cuestiones que obstaculizan que el proceso de emisión-recepción se lleve a cabo con éxito- , dado que en este contexto comunicativo los participantes involucrados en el conflicto no suelen caracterizarse por mantener una escucha activa.

A la hora de diseñar el método de análisis seguido en esta investigación, resultó necesario indagar desde el punto de vista lexicográfico en la difusa y débil frontera semántica existente en torno a los actos de habla relacionados, por un lado, con las órdenes y los mandatos y, por el otro, con las peticiones; esto es, con los actos de habla directivos. La acepción número 17 de la entrada orden en RAE-ASELE (2014) indica literalmente: «Mandato que se debe obedecer, observar y ejecutar». A la par, la primera acepción que incluye en la entrada mandato dice: «Orden o precepto que el superior da a los súbditos». En el caso del sustantivo petición, remite al verbo pedir, cuya primera acepción es: «Expresar a alguien la necesidad o el deseo de algo para que lo satisfaga».

Del mismo modo, se ha tenido en cuenta el método utilizado por investigaciones con similares intereses. Muldon (1998) para el estudio lingüístico de los actos de habla directivos propone un modelo muy interesante estructurado de la siguiente manera: (1) dimensión predicativa: explicidad, interplicidad e implicidad; (2) dimensión deíctica personal: explicidad, interplicidad e implicidad; (3) dimensión modificadora: modal, imperativa, performativa y con que; y (4) dimensión del tipo de oración: imperativos, interrogativos y declarativos. Así pues, con miras a efectuar un análisis de las diferentes construcciones en español para manifestar una petición, Iglesias Recuero (2016) se sirve de esta clasificación: (1) enunciados en imperativo o subjuntivo, (2) expresiones realizativas, (3) aserciones volitivas, (4) aserciones deónticas, (5) otros enunciados aseverativos y (6) enunciados interrogativos. En cambio, en Siebold (2008: 85) se catalogan cinco estrategias de petición, las cuales presentan gradaciones que parten de la descortesía para desembocar en la cortesía: petición derivable de modo imperativo, petición derivable de la locución, petición por medio de una pregunta directa, petición a través de la expresión de deseo y petición por medio de una referencia a las condiciones preparatorias. 
Tomando estos métodos como base, se ha creado una taxonomía que se basa en tales análisis investigadores - principalmente de Iglesias Recuero (2016) y Siebold (2008) - , pero, por supuesto, también atiende a las necesidades del corpus específico de mediaciones laborales estudiado. En concreto, se han hallado ocho formas de cifrar los actos de habla directivos mediante el empleo de: (1) modo imperativo, (2) perífrasis verbal de obligación, (3) presente del modo indicativo, (4) presente del modo subjuntivo, (5) oración subordinada circunstancial condicional, (6) pretérito imperfecto del modo indicativo, (7) infinitivo e (8) interrogación. En función de esta clasificación, se aportan datos cuantitativos y cualitativos del corpus examinado, con la finalidad de facilitar no solo información relativa a la frecuencia de uso, sino también diversas transcripciones que ejemplifican tales tipologías.

\section{ANÁLISIS Y RESULTADOS}

Para efectuar el análisis de la presente investigación, se ofrecen, en primer lugar, datos cuantitativos, para, enseguida, abordar aspectos cualitativos. En la tabla 1 quedan reflejados de forma conjunta los resultados obtenidos. En el corpus aquí analizado hay una marcada preferencia por la utilización de enunciados que contienen el imperativo y la perífrasis verbal de obligación. De esta manera, el imperativo es la opción elegida con mayor frecuencia en el corpus de mediaciones laborales, alcanzando el $41.9 \%$ de los casos en que se utiliza un acto de habla directivo. A continuación, con un orden descendente de uso, se hallan con gran diferencia estadística: la perífrasis verbal de obligación (17.1\%), el presente de indicativo (13.8\%), el presente de subjuntivo $(10.4 \%)$, la oración condicional (6\%), el pretérito imperfecto de indicativo (3.8\%), el infinitivo (3.8\%) y la interrogación $(2.7 \%)$.

\begin{tabular}{|l|c|c|}
\hline & Frecuencia absoluta & Frecuencia \% \\
\hline Imperativo & 76 & $41.9 \%$ \\
\hline Perífrasis verbal de obligación & 31 & $17.1 \%$ \\
\hline Presente de indicativo & 25 & $13.8 \%$ \\
\hline Presente de subjuntivo & 19 & $10.4 \%$ \\
\hline Oración condicional & 11 & $6 \%$ \\
\hline Pretérito imperfecto de indicativo & 7 & $3.8 \%$ \\
\hline Infinitivo & 7 & $3.8 \%$ \\
\hline Interrogación & 5 & $2.7 \%$ \\
\hline Total & 181 & $100 \%$ \\
\hline
\end{tabular}

TABLA 1. Datos globales de la frecuencia absoluta y la frecuencia porcentual de los actos de habla directivos en el corpus de mediaciones laborales 
Al estudiar la frecuencia de empleo en función de los roles de los participantes, se obtienen resultados bastante diferentes en algunos casos. En las mediaciones laborales los actores se dividen en tres grupos: la comisión, la parte empresarial y la parte trabajadora. El imperativo presenta los mayores porcentajes en los tres grupos, si bien difiere su estadística de uso: $34.6 \%$ en el caso de la comisión, $39.2 \%$ en la parte empresarial y $50.6 \%$ en la parte trabajadora. La comisión posee esta preferencia de utilización: presente de indicativo $(23 \%)$, presente de subjuntivo $(10.2 \%)$, perífrasis verbal de obligación $(8.9 \%)$, oración condicional $(8.9 \%)$, pretérito imperfecto de indicativo $(7.6 \%)$, infinitivo (3.8\%) e interrogación (2.5\%). En cambio, la parte empresarial (28) tiene una frecuencia absoluta de empleo de actos de habla directivos muy inferiores a la comisión (78) y a la parte trabajadora (75). Además, la parte empresarial opta en mayor medida por el uso de la perífrasis verbal de obligación (28.5\%), seguida del presente de subjuntivo (17.8\%), el presente de indicativo $(10.7 \%)$ y el infinitivo $(3.5 \%)$, de manera que no utiliza en ninguna ocasión la oración condicional, el pretérito imperfecto de indicativo o la interrogación. Junto a ello, la parte trabajadora recurre en orden descendente de asiduidad a la perífrasis verbal de obligación $(21.3 \%)$, el presente de subjuntivo ( $8 \%$ ), el presente de indicativo $(5.3 \%)$, la oración condicional $(5.3 \%)$, el infinitivo (4\%), la interrogación ( $4 \%$ ) y el pretérito imperfecto de indicativo $(1.3 \%)$.

\begin{tabular}{|l|c|c|c|c|c|c|}
\hline & \multicolumn{2}{|c|}{ Comisión } & \multicolumn{2}{c|}{ Empresa } & \multicolumn{2}{c|}{ Trabajadores } \\
\hline & $\begin{array}{c}\text { Frecuencia } \\
\text { absoluta }\end{array}$ & $\begin{array}{c}\text { Frecuencia } \\
\%\end{array}$ & $\begin{array}{c}\text { Frecuencia } \\
\text { absoluta }\end{array}$ & $\begin{array}{c}\text { Frecuencia } \\
\%\end{array}$ & $\begin{array}{c}\text { Frecuencia } \\
\text { absoluta }\end{array}$ & $\begin{array}{c}\text { Frecuencia } \\
\%\end{array}$ \\
\hline Imperativo & 27 & $34.6 \%$ & 11 & $39.2 \%$ & 38 & $50.6 \%$ \\
\hline Perífrasis verbal de obligación & 7 & $8.9 \%$ & 8 & $28.5 \%$ & 16 & $21.3 \%$ \\
\hline Presente de indicativo & 18 & $23 \%$ & 3 & $10.7 \%$ & 4 & $5.3 \%$ \\
\hline Presente de subjuntivo & 8 & $10.2 \%$ & 5 & $17.8 \%$ & 6 & $8 \%$ \\
\hline Oración condicional & 7 & $8.9 \%$ & - & - & 4 & $5.3 \%$ \\
\hline Pretérito imperfecto de indicativo & 6 & $7.6 \%$ & - & - & 1 & $1.3 \%$ \\
\hline Infinitivo & 3 & $3.8 \%$ & 1 & $3.5 \%$ & 3 & $4 \%$ \\
\hline Interrogación & 2 & $2.5 \%$ & - & - & 3 & $4 \%$ \\
\hline Total & 78 & $100 \%$ & 28 & $100 \%$ & 75 & $100 \%$ \\
\hline
\end{tabular}

TABLA 2. Datos específicos según actores de la frecuencia absoluta y la frecuencia porcentual de los actos de habla directivos en el corpus de mediaciones laborales

En la tabla 3 se desglosa en frecuencia absoluta el ciframiento de los actos de habla directivos teniendo en cuenta tanto el grupo al que pertenecen los participantes 
como - a diferencia del cuadro precedente - el desglose de manera individual de los datos de las cinco mediaciones analizadas.

\begin{tabular}{|l|c|c|c|c|c|c|c|c|c|c|c|c|c|c|c|}
\hline & \multicolumn{4}{|c}{ Comisión } & \multicolumn{4}{|c|}{ Empresa } & \multicolumn{5}{c|}{ Trabajadores } \\
\hline & M1 & M2 & M3 & M4 & M5 & M1 & M2 & M3 & M4 & M5 & M1 & M2 & M3 & M4 & M5 \\
\hline Imperativo & 11 & 3 & 1 & 4 & 8 & 1 & 1 & - & 3 & 6 & 4 & - & 2 & 6 & 26 \\
\hline $\begin{array}{l}\text { Perífrasis verbal de } \\
\text { obligación }\end{array}$ & 4 & 2 & - & - & 1 & 8 & - & - & - & - & 7 & 1 & 1 & 1 & 6 \\
\hline Presente de indicativo & 9 & 1 & 3 & 3 & 2 & 1 & - & - & - & 2 & 1 & - & - & - & 3 \\
\hline Presente de subjuntivo & 2 & 3 & - & 1 & 2 & - & - & - & - & 5 & - & - & - & 1 & 5 \\
\hline Oración condicional & 6 & - & - & 1 & 1 & - & - & - & - & - & 1 & 2 & - & - & 1 \\
\hline $\begin{array}{l}\text { Pretérito imperfecto de } \\
\text { indicativo }\end{array}$ & 1 & 1 & - & 3 & 1 & - & - & - & - & - & 1 & - & - & - & - \\
\hline Infinitivo & 2 & 1 & - & - & - & 1 & - & - & - & - & - & - & 2 & - & - \\
\hline Interrogación & 2 & - & - & - & - & - & - & - & - & - & 1 & - & - & - & 2 \\
\hline
\end{tabular}

TABLA 3. Datos específicos en frecuencia absoluta según actores y mediaciones de los actos de habla directivos existentes en el corpus de mediaciones laborales

Para comenzar el análisis cualitativo, se mostrarán distintos ejemplos de empleo del imperativo por parte de los tres grupos existentes en estos encuentros comunicativos. En el ejemplo (1) — que es la intervención de un miembro de la comisión- se aprecian dos imperativos emitidos de forma consecutiva. Este ejemplo (1) pone de manifiesto cómo se utilizan formas tradicionalmente asociadas a la cortesía («perdona»), si bien el miembro 1 de la comisión se sirve del modo imperativo para pedir al alocutario que termine su turno de habla; en este caso en concreto, esta intervención tiene lugar al comienzo del acto mediador. En el ejemplo (2), quien pronuncia el imperativo es un miembro de la empresa y de manera explícita pide el turno de habla en el desarrollo de la negociación. También durante la confrontación de hechos, en el ejemplo (3) la acompañante 2 - la cual pertenece al grupo de los trabajadores - usa el imperativo del verbo perdonar para corregir al representante de la empresa. Por tanto, estos fragmentos demuestran que, al analizar estas secuencias discursivas desde la perspectiva de la pragmática, expresiones que tradicionalmente se han considerado corteses pueden resultar descorteses en determinados contextos o justamente al revés, puesto que el modo imperativo tradicionalmente ha sido entendido como muy descortés; sin embargo, en las mediaciones laborales su uso no resulta especialmente hiriente en bastantes casos.

1) 12- Miembro 1 de la Comisión: ${ }^{\circ}(\text { perdona / termine })^{\circ}(()) \S[$ Mediación 4] 
2) 141- Representante de los trabajadores: es que me dijiste me dijiste que en junio que cuando vinieras de Valencia en junio] que se iba a hacer en julio / ahora otro más § 142- Representante 1 de la empresa: déjame que te hable que [(( ))

143- Representante de los trabajadores: sííi (( ))] es que nos estás tomando el pelo $\S$ [Mediación 1]

3) 129- Acompañante 2: se ganó / se ganó [(( ))

130- Representante 1 de la empresa: (( ))]

131- Acompañante 2: =de ocho / usted perdone / de ocho a seis de la tarde se ganó §

132- Acompañante 3: (( )) §

133- Acompañante 2: a seis de la tarde / perdón / de ocho de la mañana a seis de [la tarde [Mediación 4]

Aunque menos descortés que el imperativo, la perífrasis verbal de obligación castiga severamente la imagen negativa de los destinatarios. En el ejemplo (4), que se produce casi al final de la mediación, el asesor de los trabajadores emplea dos perífrasis con la construcción tener que + infinitivo cuyo receptor es el representante de la empresa:

4) 801- Presidente de la Comisión: eh si os parece]

802- Asesor de los trabajadores: =y lo que tengas que negociar luego con la dirección y la agencia del hospital lo ten[drás que hacer

803- Representante de los trabajadores: era el] inciso era (( )) § [Mediación 5]

El presente de indicativo puede ser utilizado para cifrar un acto de habla directivo. En el ejemplo (5), extraído de la parte inicial de la mediación laboral 3, el presidente de la comisión termina de hacer la presentación de la sesión y cede la palabra a la parte trabajadora. Se trata de un acto de habla en el que el emisor explícitamente está pidiendo al receptor que haga algo, en este caso en concreto que asuma el turno de habla para explicar los motivos por los que han solicitado la celebración del acto mediador:

5) 12- Presidente de la Comisión: eh (risa) queee viene de la Universidad hoy aaa a tomar algún algún apunte algún dato acerca de de cuál eees el funcionamiento / ella está trabajando en una tesis doctoral yyy yyy un es también otro motivo de satisfacción para el Sercla que que se que desde laaa que desde el ámbito universitario seee se interesen por eeeh este SISTEMA que hemooos parido eeeh las organizaciones que se encuentran hoyyy en esta mesa / y ya sin más preámbulos vamos aaa a pasar a iniciar el Sercla / 
eeeh tiene la palabra los compañeros que plantean que inician este este este expediente /// (3") [Mediación 3]

En el corpus de mediaciones laborales aquí analizado se cifran en distintas ocasiones actos de habla directivos con el adverbio de negación por excelencia seguidos de verbos en presente de subjuntivo. En el ejemplo (6) el representante de la empresa, cuando está sentando las bases de la negociación, sigue tal construcción para informar al grupo de los trabajadores que no va a permitir que se hable del acuerdo que habían firmado con anterioridad dado que conoce dicha información:

6) 129- Representante 1 de la empresa: =ahora no me vengas a explicar tú el acuerdo / tú ahora no me vengas a explicar el acuer[do / [Mediación 5]

El ejemplo (7), en el que el miembro 2 de la comisión pronuncia hasta en tres ocasiones la prótasis, refleja, una vez más, la pugna constante que hay por obtener el turno de habla, si bien es cierto que normalmente al comienzo del acto mediador no suele haber lucha por obtener el control del discurso. Con esta estructura condicional, el hablante en realidad está pidiendo a su interlocutor que le ceda la palabra, a pesar de que no tiene éxito, ya que el representante de los trabajadores continúa con su discurso donde queda latente el malestar existente en la plantilla de la empresa:

7) 52- Representante de los trabajadores: las priorida]=des es una persona que está realizando [un trabajo que / que que tiene que cobrar

53- Miembro 2 de la Comisión: $\underline{\text { si me permitís si me permitís] por favor si me permitís }}$ vamos a ver yo creo que hay un acuerdo entre las [partes

54- Representante de los trabajadores: ya le] puedes estar dando vueltas a la cosa que las personas tienen que cobrar lo que [están trabajando [Mediación 1]

El empleo del tiempo verbal pretérito imperfecto del modo indicativo con la finalidad de emitir un acto de habla directivo es poco recurrido en el corpus analizado. En el ejemplo (8) se aprecia cómo el presidente de la comisión reitera este tiempo verbal con querer, el cual es un verbo volitivo. Una vez más, el objetivo de este acto de habla se centra en conseguir la palabra, hecho que resulta bastante complejo cuando las partes están estableciendo acuerdos, a pesar de que no tiene intención de asumir el turno, sino de distribuirlo, cometido que asume la comisión:

8) 879- Presidente de la Comisión: sí] / eh por favor quería quería primero primero hacer un inciso ella y después tiene la palabraaa \{nombre del del representante 2 de la empresa\} $\S[$ Mediación 5] 
En el ejemplo (9), en pleno proceso negociador, el representante de la empresa encabeza su intervención reiterando un infinitivo en posición inicial absoluta. Aunque se trate de una construcción gramaticalmente incorrecta, conviene señalar que es un error muy extendido sobre todo en el plano oral de la lengua; aparte, tampoco queda claro si este hablante ha empezado el turno de habla antes y no ha sido transcrito porque estaban hablando de manera simultánea distintos participantes:

9) (hablan varias personas a la misma vez)

243- Representante 1 de la empresa: ver ver si las funciones que realiza el trabajador son las que corresponden al encuadramiento profesional que tiene / y si no le corresponden al encuadramiento clasificarlo adecuadamente $\S$

244- Representante de los trabajadores: ${ }^{\circ}\left(\right.$ correcto $^{\circ}{ }^{\mathrm{o}}$ [Mediación 1]

La utilización de una interrogación puede ser ejemplo de un acto de habla directivo, en tanto que el emisor le está pidiendo al receptor que realice una acción concreta. En el ejemplo (10), que se sitúa en la fase de exposición de posturas, la asesora de Comisiones Obreras le solicita al representante de los trabajadores que le aporte una documentación para poder consultar su contenido; por el comienzo de la intervención de la asesora de Comisiones Obreras se puede entender que ella sí creía que el representante de los trabajadores llevaba dicha documentación:

10) 383- Asesora de Comisiones Obreras: quiero leer una cosa / ¿que si la tienes ahí? / 384- Representante de los trabajadores: ${ }^{\circ}(\text { nooo })^{\circ} / /$ [Mediación 5]

\section{CONCLUSIONES}

Las conclusiones a las que llega este artículo pueden ser sintetizadas en cinco puntos:

1. Desde que Austin (1962) y Searle (1969 y 1975) dieron a conocer su teoría de los actos de habla - la cual supuso un pilar fundamental en el campo de la pragmática - son muchos los investigadores que se han interesado en este tema. La aportación efectuada por tales filósofos del lenguaje logró romper con la concepción milenaria del positivismo lógico que defendía que la lengua tenía únicamente función descriptiva (Ballesteros Martín 1999: 51). Por supuesto, bastantes críticos han puesto el punto de mira en las sombras existentes en estos postulados, pero, pese a las críticas recibidas, la teoría de los actos de habla ha conseguido «cambiar el rumbo de los estudios lingüísticos» (Ridao 2010: 128). 
2. Los actos de habla permiten realizar acciones; en el caso concreto de los actos de habla directivos, su función se acota a que — en palabras de Molina (2008: 18) - un emisor traslada al receptor la carga de acción. Así mismo, se ha de tener en cuenta que en bastantes ocasiones resulta muy complicado discernir si un acto de habla es una petición o una orden o un mandato, de ahí que en este artículo se haya preferido utilizar la denominación global de actos de habla directivos. A la hora de cifrarlos lingüísticamente, el emisor se encuentra con un abanico de opciones que oscilan entre la cortesía y la descortesía; las estrategias de cortesía negativa resultan ser las más corteses, seguidas de la falta de cortesía y en último lugar la descortesía (Haverkate 1994: 152).

3. En la metodología se ha tomado como referencia el trabajo de Iglesias Recuero (2016) y, en menor medida, el estudio de Siebold (2008), si bien el método investigador ha sido diseñado ad hoc en función de las necesidades del corpus de mediaciones laborales. En el análisis cuantitativo - según los datos globales - se observa un elevado empleo del imperativo (41.9\%), frente a la perífrasis verbal de obligación $(17.1 \%)$, el presente de indicativo (13.8\%), el presente de subjuntivo (10.4\%) y la oración condicional (6\%), existiendo un porcentaje muy bajo en el pretérito imperfecto de indicativo (3.8\%), el infinitivo (3.8\%) y la interrogación (2.7\%). La parte empresarial emite una cantidad de actos de habla directivos bastante inferior a la comisión y la parte trabajadora, que alcanza en frecuencia absoluta 28,78 y 75 respectivamente. Ello demuestra un predominio de recursos lingüísticos relacionados con la descortesía, frente a un bajo empleo de recursos menos impositivos, lo cual manifiesta que la relación entre ambas partes se caracteriza por la sensación de hastío e insatisfacción que sienten los trabajadores que deja en suspenso la relación de poder dispar existente entre ambas partes.

4. Desde el enfoque cualitativo, los resultados encontrados en el corpus de mediaciones laborales presentan afinidad con las aseveraciones expuestas por Núñez (1991: 357-358), en tanto que el modo imperativo obtiene una alta frecuencia de uso, si bien el porcentaje correspondiente con el subjuntivo es bastante bajo, al igual que ocurre con el empleo de verbos modales. El presente artículo — en consonancia con Haverkate (1994: 156) - aboga por analizar los intercambios comunicativos desde un enfoque pragmático, dado que la valoración de si el acto de habla resulta cortés o descortés no se ha de centrar únicamente en la estructura lingüística con la que ha sido cifrado, sino que también hay que valorar las variables pragmáticas; Pérez Hernández (2000: $385)$ las sintetiza en: opcionalidad, grado de directividad del acto e indirección, costo/ beneficio, poder social y distancia social. En el contexto comunicativo sometido a análisis, se observa que, frente a las diferentes opciones de ciframiento lingüístico, 
los participantes presentan una clara preferencia por emitir actos de habla directos y con una evidente carga impositiva para el receptor, habida cuenta de la existencia de una relación propia entre empleadores y empleados, con su consecuente costo/ beneficio por ambas partes, a la vez que hay diferente nivel tanto de poder como de distancia social.

5. Enlazando los datos cuantitativos y cualitativos, se ha de precisar que los trabajadores constituyen el grupo que emite una cifra más elevada de verbos en forma imperativa (38 en frecuencia absoluta), frente a la comisión (27) y la parte empresarial (11). Ello puede interpretarse como una actitud impositiva, que a través del uso del imperativo está comunicando la vía para llegar a un acuerdo que solvente los problemas derivados de las condiciones laborales. Del mismo modo, las perífrasis verbales de obligación exponen la acción ilocutiva del emisor que cifra este acto de habla directivo. En consonancia con los resultados cuantitativos existentes en el empleo del imperativo, los trabajadores conforman el colectivo que recurre con mayor asiduidad a la utilización de la perífrasis verbal de obligación (16 en frecuencia absoluta), seguida de la parte empresarial (8) y la comisión (7). El resto de tipologías presenta una frecuencia bastante más baja, con la excepción del uso del presente de indicativo por parte de la comisión (18); aparte, el presente del indicativo, el presente del subjuntivo, la oración condicional, el pretérito imperfecto de indicativo, el infinitivo o la interrogación poseen como denominador común mostrar veladamente la intención ilocutiva del hablante.

\section{BIBLIOGRAFÍA}

AinciBuru, M. C. (2017): «La clasificación de los actos de habla: de la conceptualización pragmática a la identificación automatizada», en A. L. Duffé Montalván (ed.): Singularidad y novedad en los estudios sobre los actos de habla. Madrid: Síntesis, pp. 21-51.

Almeida CABREJAs, B. (2011): «La formulación lingüística del mandato y la prohibición en varios textos historiográficos medievales castellanos», Cahiers d'Études Hispaniques Médiévales 34, pp. 185-199. https://doi.org/10.3406/cehm.2011.2262 Austin, J. (1962): How to do things with words. Cambridge: Harvard University Press. Ballesteros Martín, F. J. (1999): La cortesía verbal: análisis pragmático lingüístico en las exhortaciones impositivas en inglés y en español: el ruego y el mandato. Tesis doctoral. Departamento de Filología Inglesa. Universidad Complutense de Madrid. 
BINTI IsMAIL, R. (2013): Análisis contrastivo de la cortesía verbal en español y malayo en la realización de tres actos de habla; petición, mandato y rechazo. Tesis doctoral. Departamento de Lengua Española. Universidad de Valladolid.

BRIz, A. (1998): El español coloquial en la conversación. Esbozo de pragmagramática. Barcelona: Ariel.

Brown, P. \& S. LeVInson (1987): Politeness: some universals in language usage. Cambridge: Cambridge University Press. https://doi.org/10.1017/CBO9780511813085

Calsamiglia, H. \& A. Tusón (1999): Las cosas del decir. Manual de análisis del discurso. Barcelona: Ariel.

Cisneros Estupiñán, M. (2007): «Atenuación de los mandatos y las peticiones en la exprovincia de Obando», Lenguaje 35(1), pp. 29-46.

Cuamba Herrejón, J. C. (2014): «La apropiación habermasiana y deleuzeana de la teoría de los actos de habla de Austin y Searle», Devenires XV, pp. 83-103.

DotToRI, A. (2019): «La teoría de los actos de habla y su relevancia sociológica», Revista Mexicana de Ciencias Politicas y Sociales 64(235), pp. 165-188. https:// doi.org/10.22201/fcpys.2448492xe.2019.235.63020

DufFé Montalván, A. L. (2017): «Los actos de habla y las fases de enseñanza-aprendizaje en los manuales de ELE y FLE», en A. L. Duffé Montalván (ed.): Singularidad y novedad en los estudios sobre los actos de habla. Madrid: Síntesis, pp. 171-213.

GARCíA FernÁNDEZ, M. E. (2010): Aspectos pragmáticos reflejados en un fragmento de La Celestina de Fernando de Rojas: actos de habla, dialogismo y cortesía verbal. España: Editorial Edita.

Garrido Medina, J. (1999): «Los actos de habla: las oraciones imperativas», en V. Demonte \& I. Bosque (coords.): Gramática descriptiva de la Lengua Española. Volumen III. Madrid: Espasa, pp. 3879-3928.

Gutiérrez OrdóÑez, S. (2002): De pragmática y semántica. Madrid: Arco/Libros. HAVERKATE, H. (1994): La cortesía verbal. Estudio pragmalingüistico. Madrid: Gredos. HeRnÁndeZ Toribio; M. I \& L. MARIotTini (2018): «Actos de habla y atenuación 2.0: TripAdvisor», Círculo de Lingüistica Aplicada a la Comunicación 73, pp. 15-32. https://doi.org/10.5209/CLAC.59057

Iglesias Recuero, S. (2010): «Aportación a la historia de la (des)cortesía: las peticiones en el siglo XVI», en F. Orletti \& L. Mariottini (eds.): (Des)Cortesía en español: espacios teóricos y metodológicos para su estudio. Actas del IV 
Congreso Internacional del Programa EDICE. Roma-Estocolmo: Università degli Studi Roma Trè-EDICE-Universidad de Estocolmo, pp. 369-396.

IgLESIAs Recuero, S. (2016): «Otra cara de la pragmática histórica: la historia de los actos de habla en español: peticiones y órdenes en las Novelas Ejemplares de Miguel de Cervantes», en A. López Serena, A. Narbona \& S. del Rey Quesada (coords.): El español a través del tiempo: estudios ofrecidos a Rafael Cano Aguilar. Sevilla: Universidad de Sevilla, pp. 971-994.

MolinA, T. (2008): «Los actos directivos, estrategias reguladoras de la cortesía verbal en el discurso oral académico», Revista Informe de Investigaciones Educativas XXII(2), pp. 15-28.

Morales Manrique, E. (2010): El imperativo: formas y funciones. Propuestas para su enseñanza en el español como lengua extranjera. Tesis doctoral. Departamento de Lingüística General y Teoría de la Literatura. Universidad de Granada.

MORRIS, C. (1938): «Foundations of the theory of signs», International Encyclopedia of Unifies Science 1, 2. https://doi.org/10.3406/lgge.1974.2263

Muldon, G. (1993): «¿Por qué no coges el teléfono? Acerca de los actos de habla indirectos», Diálogos Hispánicos 12, pp. 181-208.

Muldon, G. (1998): «Un estudio empírico de los actos de habla directivos en español», Diálogos Hispánicos 22, pp. 237-276.

MunduATE, L. et alii (2008): Guía para la mediación laboral. http://www.mediacion. icav.es/wp-content/uploads/2018/01/GUIA-MEDIACI\%C3\%93N-LABORALTHELMA-BUTTS-1.pdf

NúÑEZ, S. (1991): «Hacia una tipología de los actos de habla directivos en latín», Florentia Iliberritana 2, pp. 357-375.

PÉrez HERnÁndez, L. (2000): «Cómo conseguir que la gente obedezca tus palabras: un análisis cognoscitivo de las órdenes en español», Revista Española de Lingüística Aplicada extra 1, pp. 375-393.

Querol Bataller, M. (2018): «Peticiones en la conversación en lengua china: metodología para la comparación interlingüística», ELUA 32, pp. 263-289. https:// doi.org/10.14198/ELUA2018.32.12

RAE-ASALE (2009): Nueva Gramática de la Lengua Española. Madrid: Espasa.

RAE-ASALE (2014): Diccionario de la Lengua Española. Madrid: Espasa.

REDONDO GonzÁLEZ, M. (2018): La enseñanza de la cortesía mitigadora en la clase de ELE a alumnos ingleses. Trabajo Fin de Máster. Comillas: Universidad Pontificia de Comillas. 
REYes, G. (1994[1990]): La pragmática lingüistica. El estudio del uso del lenguaje. Barcelona: Montesinos.

RIDAO, S. (2009): Las mediaciones laborales. Materiales para su estudio lingüístico. Murcia: Editum. http://ibros.um.es/editum/catalog/book/381

RIDAO, S. (2010): «Aplicación de los orígenes de la pragmática a un corpus de mediaciones laborales: Austin y Searle», Pragmalingüística 18, pp. 108-129. https://revistas.uca.es/index.php/pragma/article/view/206

RIDAO, S. (2014): «El marco comunicativo en las resoluciones de conflictos: juicios, arbitrajes, conciliaciones y mediaciones», Círculo de Lingüística Aplicada a la Comunicación 57, pp. 85-112. https://doi.org/10.5209/rev_CLAC.2014. v57.44516

SeARLE, J. (1969): Speech acts: an essay on the philosophy of language. Cambridge: Cambridge University Press. https://doi.org/10.1017/CBO9781139173438

Searle, J. (1975): «Indirect speech acts», en P. Cole \& J. Morgan (eds.): Syntax and semantics. Volume 3. Nueva York: Academic Press, pp 59-82.

Shahila MAnsor, N. \& E. RidRuejo Alonso (2014): «Análisis pragmático de los actos de habla directivos en la publicidad malaya», Lenguas Modernas 44, pp. 67-79.

SIEBOLD, K. (2008): Actos de habla y cortesía verbal en español y en alemán. Frankfurt am Main: Peter Lang.

Stendhal (1987): La Cartuja de Parma. Madrid: Alianza. 


\section{ANEXo: Símbolos de transcripción}

Estos símbolos de transcripción han sido establecidos por el grupo Val.Es.Co (Briz, 1998). No obstante, las características propias del corpus transcrito han obligado la incorporación de algunos símbolos.

: Cambio de hablante.

? Interlocutor no reconocido.

$\S$ Sucesión inmediata, sin pausa apreciable, entre dos emisiones de distintos hablantes.

[ Lugar donde se inicia un solapamiento o superposición.

] Final del habla simultánea.

$=$ Mantenimiento del turno de un participante en un solapamiento.

/ Pausa corta, inferior al medio segundo.

// Pausa entre medio segundo y un segundo.

/// Pausa de un segundo o más.

(5") Silencio (lapso o intervalo) de cinco segundos; se indica el número de segundos en las pausas de más de un segundo.

EN COCHE Pronunciación marcada o enfática.

(()) Fragmento indescifrable.

((siempre)) Transcripción dudosa.

$((\ldots))$ Interrupciones de la grabación o de la transcripción.

(en)tonces Reconstrucción de una unidad léxica que se ha pronunciado incompleta.

${ }^{\circ}()^{\circ}$ Fragmento pronunciado en un tono de voz más bajo, próximo al susurro.

(risas) Sonidos significativos e información no verbal.

aaa Alargamientos vocálicos.

nnn Alargamientos consonánticos.

¿i !? Preguntas o exclamaciones retóricas (por ejemplo, las interrogaciones exclamativas: preguntas que no preguntan).

¿? Interrogaciones. También para los apéndices del tipo «¿no?», «¿eh?», «¿sabes?».

i! Exclamaciones. Expresiones irónicas.

Letra cursiva Reproducción e imitación de emisiones. Estilo directo, característico de los denominados relatos conversacionales.

+()$+$ Fragmentos del discurso en los que se emplea un ritmo de habla muy acelerado.

-( )- Fragmentos del discurso en los que se emplea un ritmo de habla muy pausado.

\{\} Información confidencial. Por ejemplo, nombres y apellidos, o nombres de calles, pueblos o ciudades, números identificativos como el Documento Nacional de Identidad, entre otros. 